\title{
Design \& Fabrication of PVC Bladed Inexpensive Wind Turbine
}

\author{
Vicky K Rathod ${ }^{1}$, Prof.S.Y.Kamdi ${ }^{2}$ \\ ${ }^{I}$ Student of M Tech (Energy Management System), Department of Electrical Engineering, Rajiv Gandhi \\ College of Engineering Research \& Technology, Chandrapur (M.S), India \\ ${ }^{2}$ Professor, Department of Electrical Engineering, Rajiv Gandhi College of Engineering Research \& \\ Technology, Chandrapur (M.S), India
}

\begin{abstract}
The objective of this paper is to demonstrate that PVC blade profile has better power capacity. Creates scope for designing \& Performance evaluation of a specially designed micro wind turbine for area especially in plateau region where velocity of wind is low, invariable average and dry, so where large wind turbine doesn't give satisfactory result. The small wind turbine and their wide scope of application need the comprehensive attempt to be taken place. The small wind turbine i.e. multi blade turbine with increase in number of blades can be run successfully with proper adjustment of swept area and angle of attack. The advantage of the micro wind turbine is that, apart from its low cost, it can be propelled by a wind speed as low as $2 \mathrm{~m} / \mathrm{s}$.It is the renewable source of energy which is the clean source. It can be installed over the houses for power generation in our local areas because of low cost and being of economical. Using of small wind turbines for house hold would result in fewer burdens on grid and also plays a vital role in reducing utilization of conventional energy and mobility to utilize the power.
\end{abstract}

Keywords: Angle of attack, Swept Area, Micro Wind Turbine, PVC Blade profile, Propelled.

\section{Introduction}

There are various small wind turbines designs already exist which are simple and cost effective, but there is little literature available in the Selection of main designs Parameter as per geographical Location, wind Pattern \& its Profile. Design selections are usually driven by the individual's previous experiences and level of expertise. The main motivation behind this project is to feed into the existing knowledge base with appropriate technology \& applications for the developing world. Building on the recent explosion of mobile phone use, there is a huge market for affordable charging solutions in rural off-grid locations. Current solutions include solar charging and pre-charged car batteries, but there are many locations where wind energy could do the job. From a supply chain point of view, the advantage of a wind based charging solution is that, the majority of materials required are easily available in local market. Recent work by Practical Action in Dalhousie India suggests that hand built 100W machine with wooden blades for off-grid battery charging Where in Peru and Sri Lanka would cost approximately RS 8000 . $[1,3,4]$.Wind energy is rapidly emerging as one of the most cost effective form of renewable energy with very significant increase in installed capacity being reported around the world. Since market demand is high, the development of wind energy technology has been moving very fast in many new dimensions, such as aerodynamics, structural mechanics and mechanical engineering. $[1,2,4]$

\subsection{Wind turbine working Principle}

\section{Methodology}

Wind is caused by air flowing from high pressure region to low pressure region. Pressure difference is due to uneven heating of Earth Surface. Because air has mass and it moves to form wind, it has kinetic energy.Every wind generator, whether they produce enough energy to power a city or to power a small radio, works on these same basic principles:

$\checkmark$ The wind blows

$\checkmark \quad$ Blades attached to an alternator/generator experience the force of lift and begin to spin

$\checkmark$ The generator's vane (tail) causes it to turn into the wind

$\checkmark$ The spinning creates electricity for us to use directly or to charge batteries.

\subsection{Aerodynamic Principles of Wind Turbines \\ $\checkmark$ Nomenclature \\ $\mathrm{C}_{\mathrm{L}}$ Lift coefficient \\ $\mathrm{C}_{\mathrm{D}}$ Drag coefficient \\ $\alpha \quad$ Angle of attack \\ $\rho$ Air density \\ $\mathrm{r} \quad$ Local blade radius}


L Blade chord

$\theta \quad$ Twist angle

$\varphi \quad$ Inflow angle

$\omega$ Blade angular velocity

a Axial induction factor

$\mathrm{V}_{0}$ Wind velocity at hub height

$\mathrm{V}_{\text {rel }}$ Resultant wind velocity

Blade designs to operate on either the principle of drag or lift. $[3,5]$

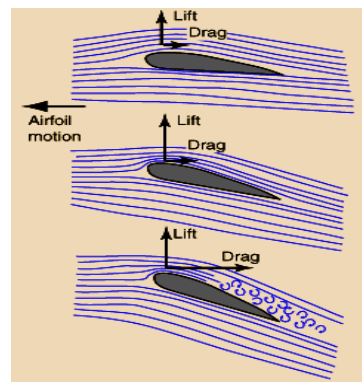

Fig.1 Show action of Drag \& Lift

\subsubsection{Drag Design}

Drag force is the force parallel to the direction of the oncoming air flow due both to viscous friction forces at the surface of the blade and to unequal pressure on the blade surfaces facing toward and away from the oncoming flow. For the drag design, the wind literally pushes theblades out of the way. Drag powered wind turbines are characterized by slower rotational speeds and high torque capabilities. They are useful for the pumping, sawing or grinding work that Dutch, farm and similar "work-horse" windmills perform. For example, a farm-type windmill must develop high torque at start-up in order to pump, or lift, water from a deep well. [5]

\subsubsection{Lift Design}

Lift force is the force perpendicular to direction of the

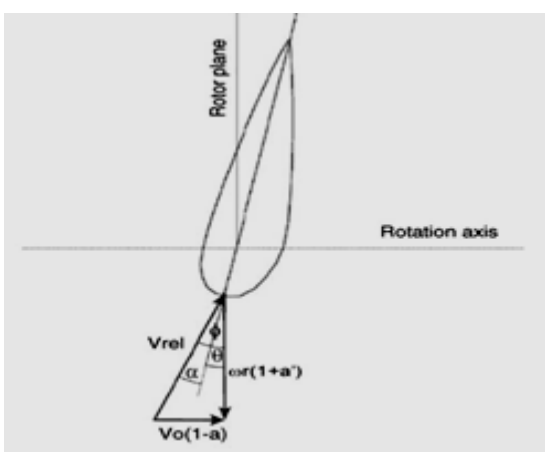

Fig.2 Blade Velocity Diagram oncoming air flow as a consequence of the unequal pressure on the upper and lower surfaces of blade. The lift blade designs to employs the same principle that enables airplanes, kites and birds to fly. The blade is essentially an airfoil, or wing. When air flows past the blade, a wind speed and pressure differential is created between the upper and lower blade surfaces. The pressure at the lower surface is greater and thus acts to "lift" the blade. When blades are attached to a central axis, like a wind turbine rotor, the lift is translated into rotational motion. Lift-powered wind turbines have much higher rotational speeds than drag types and therefore well suited for electricity generation.

$[3,5]$

$$
\begin{aligned}
& \text { Lift }=\frac{1}{2} * \rho * \mathrm{C}_{\mathrm{L}} * \mathrm{c} * \mathrm{~L} * \mathrm{~V}_{\text {rel }}^{2} \\
& \text { Drag }=\frac{1}{2} * \rho * \mathrm{C}_{\mathrm{D}} * \mathrm{C} * \mathrm{~L} * \mathrm{~V}_{\text {rel }}{ }^{2}(2)
\end{aligned}
$$

Where

$\rho$ - Density of Air $-1.225 \mathrm{~kg} / \mathrm{m}^{3}$

$\mathrm{C}$ - Chord Length

$\mathrm{L}$ - Length of the blade element

$\mathrm{V}_{\text {rel }}$ - Relative velocity of air

$\mathrm{V}_{\mathrm{rel}}=\sqrt{\mathrm{V}_{0}^{2}+(\mathrm{r} \omega)^{2}}$

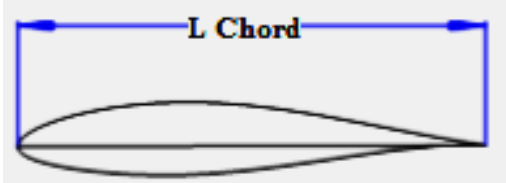

Fig. 3 NACA 63-415 Aerofoils

\subsection{Wind Speed}

\section{Design Key Parameter}

This is very important to the productivity of a windmill. The wind turbine only generates power with the wind.

\subsection{Site Selection}

\subsubsection{Location}

By figuring out the direction from which the prevailing winds in selected area usually come. It can be determine by observation during wind storms, and by looking at the trees near site. Trees that are all leaning the same direction and that have branches mostly on one side of the trunk are a good indication of prevailing wind speed and direction. Local airports and weather stations can sometimes provide this information. 3 


\subsubsection{Height}

Rotating a wind generator close to the ground is like mounting solar panels in the shade. At least Wind generator should be located at least 30 feet above without any obstruction within 300 feet in any direction. Short towers in turbulent locations cause drastically reduced power output, and extreme physical stresses on the turbine and tower.

\subsection{No of Blades \& Blade Length}

The number of blades that make up a rotor and the total area they cover affect wind turbine performance. For a lift-type rotor to function effectively, the wind must flow smoothly over the blades. To avoid turbulence, spacing between blades should be great enough so that one blade will not encounter the disturbed, weaker air flow caused by the blade which passed before it. It is because of this requirement that most wind turbines have only two or three blades on their rotors. Blade length consider as per design power output.

\subsection{Tip Speed Ratio}

The tip-speed is the ratio of the rotational speed of the blade to the wind speed. The larger this ratio, the faster the rotation of the wind turbine rotor at a given wind speed. Electricity generation requires high rotational speeds. Lift-type wind turbines have maximum tip-speed ratios of around 10, while drag-type ratios are approximately 1 . Given the high rotational speed requirements of electrical generators, it is clear that the lifttype wind turbine is most practical for this application.

\subsection{Generators}

Different generator designs produce either alternating current (AC) or direct current (DC), and they are available in a large range of output power ratings. The generator's rating, or size, is dependent on the length of the wind turbine's blades because more energy is captured by longer blades. It is important to select the right type of generator to match your intended use. Most home and office appliances operate on 120 volt (or 240 volt), 50 cycle AC. Some appliances can operate on either AC or DC, such as light bulbs and resistance heaters, and many others can be adapted to run on DC. Storage systems using batteries store DC and usually are configured at voltages of between 12 volts and 120 volts. Generators that produce AC are generally equipped with features to produce the correct voltage ( 120 or $240 \mathrm{~V}$ ) and constant frequency (60 cycles) of electricity, even when the wind speed is fluctuating. DC generators are normally used in battery charging applications and for operating DC appliances and machinery. They also can be used to produce AC electricity with the use of an inverter, which converts DC to AC.

\subsection{Towers}

The tower on which a wind turbine is mounted is not just a support structure. It also raises the wind turbine so that its blades safely clear the ground and so it can reach the stronger winds at higher elevations. Maximum tower height is optional in most cases, except where zoning restrictions apply. The decision of what height tower to use will be based on the cost of taller towers versus the value of the increase in energy production resulting from their use. Studies have shown that the added cost of increasing tower height is often justified by the added power generated from the stronger winds. Larger wind turbines are usually mounted on towers ranging from 40 to 70 meters tall. $[3,4]$

Towers for small wind systems are generally "guyed" designs. This means that there are guy wires anchored to the ground on three or four sides of the tower to hold it erect. These towers cost less than freestanding towers, but require more land area to anchor the guy wires. Some of these guyed towers are erected by tilting them up. This operation can be quickly accomplished using only a winch, with the turbine already mounted to the tower top. This simplifies not only installation, but maintenance as well. Towers can be constructed of a simple tube, a wooden pole or a lattice of tubes, rods, and angle iron. Large wind turbines may be mounted on lattice towers, tube towers or guyed tilt-up towers. [4]

Installers can recommend the best type of tower for wind turbine. It must be strong enough to support the wind turbine and to sustain vibration, wind loading and the overall weather elements for the lifetime of the wind turbine. Tower costs will vary widely as a function of design and height. Some wind turbines are sold complete with tower. More frequently, however, towers are sold separately 


\section{Wind Turbine PVC Blade Design}

First of all quarter the pipe then draw straight line and measuring on round surface edge as shown in fig 4. Large sheet of paper is wrapped tightly to get a straight line round the pipe. With the paper wrapped round the pipe we can mark the circumference. Then paper can fold in half and mark half way round the pipe. Then in half again and get quarters of the pipes. Cut the pipe directly as per marking can be possible. As With these methods we should be able to draw good straight lines all over the pipe, dividing it lengthways into quarters. Now run saw down the pipe to cut it in half. Like so \& then again into quarters refer fig 5. Now for each four quarters two things are required.

(1) Cut out a rectangle from the base so we can easily attach it to whatever we want to. Before you do the cut, drill a hole in the corner to improve the structural integrity of the material. Once the hole is drilled cut the
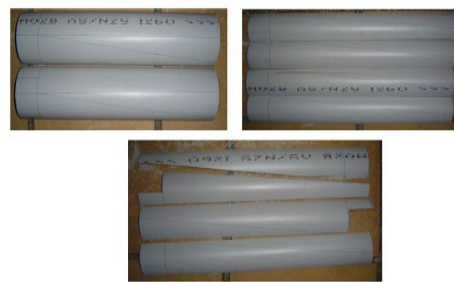

Fig. 4PVC Quarter Pipe rectangles out being careful not to cut past the hole.

(2) Cut from the high tip of the base to the point. [2]

\section{Final Product}

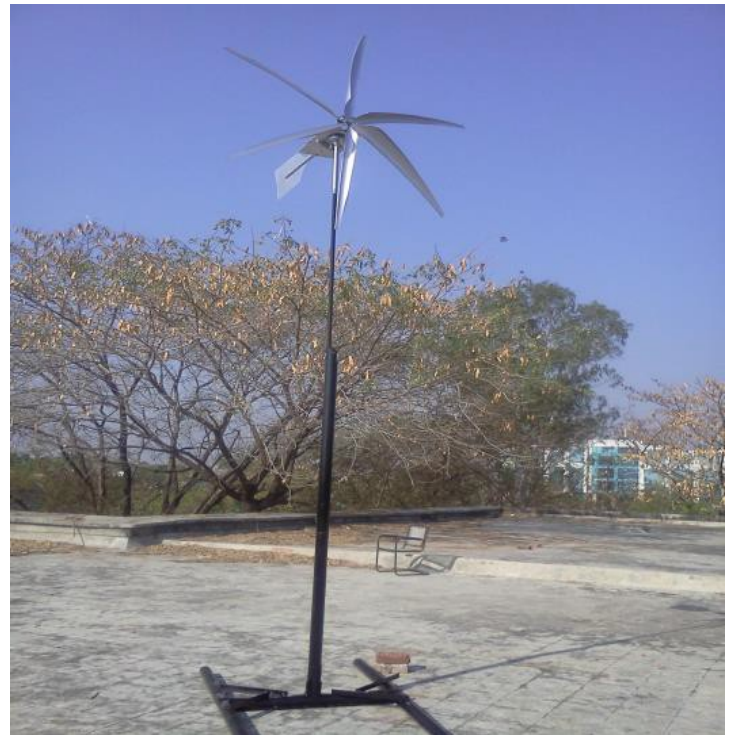

Fig. 6 Micro Wind Turbine Project under Study

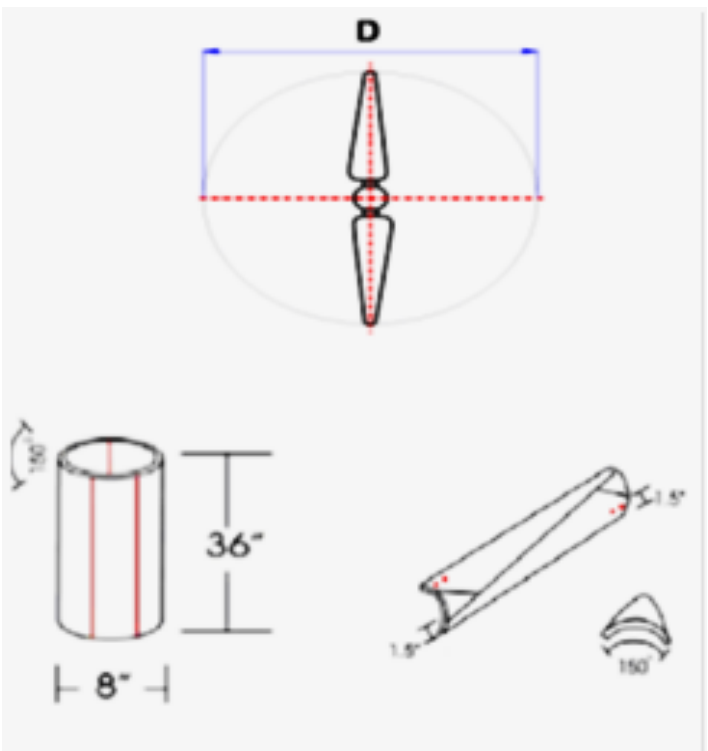

Fig. 5 Design of PVC Blade

\section{Field Testing \& Calculation for Energy Output}

Kinetic energy in (joules)

K. $\mathrm{E}=\frac{1}{2} * \mathrm{~m} * \mathrm{~V}^{2}$

Where:

$\mathrm{m}=\operatorname{mass}(\mathrm{kg})$

$\mathrm{V}=\operatorname{velocity}(\mathrm{m} / \mathrm{s})$

Note: In our area we get average wind velocity is $3-8 \mathrm{~m} / \mathrm{sec}$. $\&$ humidity is $30 \%$

Usually, we're more interested in power (which changes moment to moment) than energy. Since

Energy $=$ Power $*$ Time

And density is a more convenient way to express the mass of flowing air; the kinetic energy equation can be converted into a flow equation.

Power in the area swept by the wind turbine rotor : 
$\mathrm{P}=\frac{1}{2} * \rho * \mathrm{~A} * \mathrm{~V}^{3}$

Where:

$\mathrm{P}=$ power in watts $(746$ watts $=1 \mathrm{hp}) \&(1,000$ watts $=1$ kilowatt $)$

$\rho=$ air density (about $1.225 \mathrm{~kg} / \mathrm{m}^{3}$ at sea level, less higher up)

$\mathrm{A}=$ rotor swept area, exposed to the wind $\left(\mathrm{m}^{2}\right)$

$\mathrm{V}=$ wind speed in $\mathrm{m} / \mathrm{s}$

This yields the power in a free flowing stream of wind. Of course, it is impossible to extract all the power from the wind because some flow must be maintained through the rotor (otherwise a brick wall would be a $100 \%$ efficient wind power extractor).

So, we need to include some additional terms to get a practical equation for a wind turbine.

Wind Turbine Power :

$\mathrm{P}=\frac{1}{2} * \rho * \mathrm{~A} * \mathrm{C}_{\mathrm{p}} * \mathrm{~V}^{3} * \mathrm{~N}_{\mathrm{g}} * \mathrm{~N}_{\mathrm{B}}$

Where:

$\mathrm{P}=$ power in watts $(746$ watts $=1 \mathrm{hp}) \&(1,000$ watts $=1$ kilowatt $)$

$\rho=$ air density (about $1.225 \mathrm{~kg} / \mathrm{m}^{3}$ at sea level, less higher up)

$\mathrm{A}=$ rotor swept area, exposed to the wind $\left(\mathrm{m}^{2}\right)$

$\mathrm{C}_{\mathrm{p}}=$ Coefficient of performance (.59 Betz limit $\}$ is the maximum theoretically possible, .35 for a good design)

$\mathrm{V}=$ wind speed in $\mathrm{m} / \mathrm{s}$

$\mathrm{N}_{\mathrm{g}}=$ generator efficiency $(50 \%$ for car alternator, $80 \%$ or possibly more for a permanent magnet generator or grid-connected induction generator)

$\mathrm{N}_{\mathrm{b}}=$ gearbox/bearings efficiency (depends, could be as high as $95 \%$ if good) $[4,5]$

Tip Speed ratio for wind turbines is the ratio between the tangential speed of the tip of a blade and the actual velocity of the wind.

$\lambda=\frac{\mathrm{r} \omega}{\mathrm{v}}$

Where:

$\lambda=$ Tip speed ratio

$\mathrm{r}=$ Radius of rotor

$\mathrm{v}=$ wind velocity

We can measure the wind velocity at different places by anemometer and Turbine velocity with help of Non-contact type Tachometer now finally we consider average velocity of wind is $8 \mathrm{~m} / \mathrm{sec}$. we get approx. power $300 \mathrm{~W}$ from equation (7) at velocity $8 \mathrm{~m} / \mathrm{sec}$. Here we take TSR $=4 \&$ considering 3 blades wind turbine. The radius of the turbine is $1.02 \mathrm{~m}$. The average velocity of wind during various time periods is given table 3 .

Table: 3 Time Period Vs. Wind Velocity

\begin{tabular}{|c|c|}
\hline Time Period & Wind Velocity \\
\hline $12-1 \mathrm{PM}$ & $4.2 \mathrm{~m} / \mathrm{s}$ \\
\hline $\begin{array}{ll}1-2 & \text { PM }\end{array}$ & $5.8 \mathrm{~m} / \mathrm{s}$ \\
\hline $2-3 \quad$ PM & $2.08 \mathrm{~m} / \mathrm{s}$ \\
\hline 5-6 PM & $4.166 \mathrm{~m} / \mathrm{s}$ \\
\hline 6-7 PM & $3.58 \mathrm{~m} / \mathrm{s}$ \\
\hline $\begin{array}{ll}7-8 & \text { PM }\end{array}$ & $4.0833 \mathrm{~m} / \mathrm{s}$ \\
\hline
\end{tabular}

This setup can easily achieve 120-200 RPM in a pretty average wind of $4 \mathrm{~m} / \mathrm{s}$.

Calculating the wind turbine power without considering generator \& gear box efficiency(7):

$\mathrm{P}=286.86 \mathrm{~W}$

$$
\mathrm{P}=\frac{1}{2} * 1.225 * \pi * 1.02^{2} * 0.29 * 8^{3}
$$

We used $100 \mathrm{~V}$ DC Motor (treadmill) for measuring O/P directly. 


\section{Conclusion}

The main trend of wind turbine development is large-scale wind energy systems where annual average wind speed is high. On the other hand, a new branch of development in this field recently emerged. In regions of low wind speed and in urban areas, small or micro wind turbines are more suitable. PVC Bladed wind turbine that can be able to build by Laypersons, using readily available material which is feasible \& affordable to provide much needed electricity.PVC blade has much better power delivering capacity which can be able to propelled at low wind speed upto $2 \mathrm{~m} / \mathrm{s}$. Since most of the high wind power density regions in the zone of high wind speed are already being tapped by large scale wind turbine and so it required creating a large scope for the development of low wind speed turbines.

\section{Acknowledgements}

Author thanks to Prof.S.Y.Kamdi R.C.E.R.T College Chandrapur for his guidance \& supporting to conduct such research work.

\section{References}

[1] D.Y.C. Leung, Y. Deng, M.K.H. Leung,"Design Optimization of a Cost-Effective Micro Wind Turbine" Proceedings of the World Congress on Engineering 2010 Vol II WCE 2010, June 30 - July 2, 2010, London, U.K.

[2] Prof. H. S. Patil,"Experimental work on horizontal axis PVC turbine blade of power wind mill” IJME Volume 2 Issue 2 available on http://vixra.org/pdf/1208.0198v1.pdf

[3] Dr. S. P. Vendan, S. Aravind Lovelin, M. Manibharathi \& C. Rajkum, "Analysis of a Wind Turbine Blade Profile for Tapping Wind Power at the Regions of Low Wind Speed " IJME Volume 2 Issue 2 available on http://www.ijmejournal.com/uploads/displayVolumeIssue/ V-2-I-2-ID-1.pdf

[4] http://poisson.me.dal.ca/ dp_07_1/Downloads_files/AprilReport.pdf.

[5] http://windempowerment.org/wp-content/uploads/Blade-Element-Momentum-analysis-of-pvc-pipe-VS-wood-blades-on-a-100Wturbine.pdf.

[6] Wind Power Observatory, Mar. 2009. [Online]. Available on: www.aeeolica.es 